\title{
What factors do influence on mathematics teaching? A response using whitenization weight functions
}

\author{
Alexi Delgado, $\mathrm{PhD}^{1}$, Hipólito Reyes, $\mathrm{Mg}^{2}$ \\ ${ }^{1}$ Pontificia Universidad Católica del Perú - PUCP, Peru, kdelgadov@pucp.edu.pe \\ ${ }^{2}$ Universidad de Ciencias y Humanidades, Peru, hreyes@uch.edu.pe
}

\begin{abstract}
Mathematics is a topic very important to achieve success during learning of engineering; in this way, in this work, the teaching of mathematics from the point of the view of teachers is analysed. The approach applied in this study was the grey clustering method, which is based on grey systems theory. Specifically, the center-point triangular whitenization weight functions (CTWF) method, which is an approach based on the grey clustering method, was applied. The case study was conducted in Lima, Peru. The sample of teachers was obtained at the final stage of national competition of mathematics carried out after of previous stages of classification. The results revealed that the criteria more important that influenced on the preference from students for learning mathematics were knowledge from mathematics teacher, didactic from mathematics teacher, and motivation from mathematics teacher, in that order. The results of this study could help to teacher or educational authorities from Peru government to make the best decision on teaching and learning of mathematics. Moreover, the CTWF method showed its effectiveness during the application on the case study, and this method could be applied to other studies from social sciences or educational sciences, as the CTWF method considers the uncertainty within its analysis.
\end{abstract}

Keywords-Mathematics teaching; Grey clustering method; Mathematics learning.

\section{INTRODUCTION}

Mathematics teaching is a topic very important to teaching-learning of engineering [1]. In this way, there are studies on mathematics teaching, which research methods to teach mathematics, such as virtual laboratories [2] or interdisciplinary approach [3]. In addition, mathematics teaching also should be studied from the point of the view of teacher. In this work, the appreciation from the teachers on why students prefer mathematics is studied; for which, a group of mathematics teachers were interviewed, these teachers taught and directed to outstanding students, which participated at Mathematics National Competition commonly called CONAMAT, which was carried out in Peru [4].

In this work, the grey clustering method, which is a no probabilistic approaches that is applied on problems with high level of uncertainty or limited information, was applied [5]. In addition, the grey clustering method can be applied by means of incidence matrixes or whitenization weight functions. In this study, the center-point triangular whitenization weight functions (CTWF) method was applied, as it helps to interviewers to determine adequately their responses [5].

Digital Object Identifier (DOI):

http://dx.doi.org/10.18687/LACCEI2019.1.1.426

ISBN: 978-0-9993443-6-1 ISSN: 2414-6390
Consequently, the specific objective in this study is to analyse the perception from the teacher on why some students prefer mathematics. This analysis was conducted by applying of the CTWF method, which was carried out on a specific context from a sample of secondary teachers from Peru.

The art state about of mathematics teaching indicates that approaches provide of traditional theories or active theories, such as activity theory [6] or model of human-computer Interaction [7].

This work is organized as follows: In Section 2, the CTWF method is descripted. In section 3 , the specific case study, from Peru, is developed. In Section 4, the results and discussion are presented. Finally, in Section 5, the conclusions of this work are provided.

\section{METHOD}

In this section, the CTWF method is described; for which, it is necessary to define a set of $n$ criteria, a set of m evaluation objects, a set of s grey classes, and a set of sample values $\mathrm{x}_{\mathrm{ij}}$ $(i=1,2, \ldots, m ; j=1,2, \ldots, n)$. Then, the steps of the CTWF method can be developed as follows [8] [9]:

Step 1: The center-points of the grey clases are determined as $\lambda_{1}, \lambda_{2}, \ldots$, and $\lambda_{s}$.

Step 2: The grey classes are extended by 0 and $(s+1)$ grey classes, with their center-points $\lambda_{0}$ and $\lambda_{\mathrm{s}+1}$. Then, for the kth grey class, $k=1,2, \ldots, s$, of the $j$ th criterion, $j=1,2, \ldots, n$, for a sample value $x_{i j}$, the CTWF values are calculated by Eq. 1 .

$$
f_{j}^{k}\left(x_{i j}\right)= \begin{cases}0, & x \notin\left[\lambda_{k-1}, \lambda_{k+1}\right] \\ \frac{x-\lambda_{k-1}}{\lambda_{k}-\lambda_{k-1}}, & x \in\left[\lambda_{k-1}, \lambda_{k}\right] \\ \frac{\lambda_{k+1}-x}{\lambda_{k+1}-\lambda_{k}}, & x \in\left[\lambda_{k}, \lambda_{k+1}\right]\end{cases}
$$

Step 3: Then, the CTWF values are presented as a percentage system $\alpha_{\mathrm{k}}$ [10], which is defined by the values $\alpha_{1}=20, \alpha_{2}=40, \alpha_{3}=60, \alpha_{4}=80$, and $\alpha_{5}=100$. The final results are calculated using Eq. 2.

$$
z_{j}^{i}=\sum_{k=1}^{s} f_{j}^{k}\left(x_{i j}\right) \cdot \alpha_{k}
$$

$17^{\text {th }}$ LACCEI International Multi-Conference for Engineering, Education, and Technology: "Industry, Innovation, And Infrastructure for Sustainable Cities and Communities”, 24-26 July 2019, Jamaica. 
where $f_{j}^{k}\left(x_{i j}\right)$ is the CTWF value and $\alpha_{\mathrm{k}}$ is the percentage value of each grey class.

\section{CASE STUDY}

The case study was carried out on a mathematics competition in Peru called CONAMAT [4]. This study was conducted in eight places in Peru as shown in Fig. 1. Then, the final stage was developed in 2016 in Lima, Peru, in which attended seventy-one mathematics teachers of outstanding secondary students, this was the accessible sample for this work. In addition, in this work, we did not consider a statistical procedure to determine the sample. In this work, a qualitative approach was applied to determine the sample, this approach considers the criterion of the accessible sample [11]. Therefore, the results of this study would be valid only to sample under study.

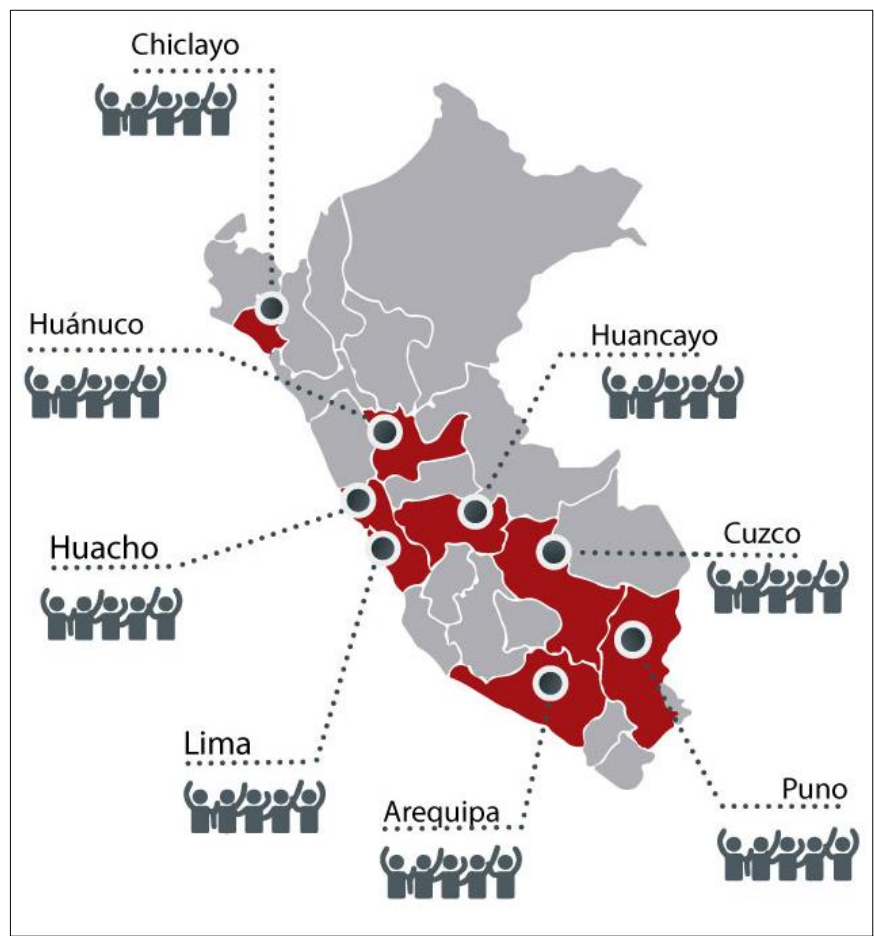

Fig. 1. Places of CONAMAT in Peru [4].

The data was collected by means of direct interviews, to teachers as shown in Fig. 2, using a structured questionnaire according to evaluation criteria defined for this study. The criteria and questions are presented in Table I.
TABLE I. EVALUATION CRITERIA IN THE CASE STUDY

\begin{tabular}{|c|c|c|c|c|c|c|}
\hline \multirow{2}{*}{\multicolumn{2}{|c|}{ Questions }} & \multicolumn{5}{|c|}{ Grey Classes } \\
\hline & & \multirow{2}{*}{ S1 } & \multirow{2}{*}{ S2 } & \multirow{2}{*}{ S3 } & \multirow[t]{2}{*}{54} & \multirow{2}{*}{ S5 } \\
\hline $\mathbf{C}_{1}$ & $\begin{array}{l}\text { What percentage does the lack of motivation, from } \\
\text { mathematics students, influence on their preference } \\
\text { to learn mathematics? }\end{array}$ & & & & & \\
\hline $\mathrm{C}_{2}$ & $\begin{array}{l}\text { What percentage does the lack of motivation, from } \\
\text { mathematics teacher to teach, influence on the } \\
\text { preference to mathematics of students? }\end{array}$ & & & & & \\
\hline $\mathbf{C}_{3}$ & $\begin{array}{l}\text { What percentage does the lack of didactic, from } \\
\text { mathematics teacher to teach, influence on the } \\
\text { preference to mathematics of students? }\end{array}$ & & & & & \\
\hline $\mathrm{C}_{4}$ & $\begin{array}{l}\text { What percentage does the lack of knowledge, from } \\
\text { mathematics teacher to teach, influence on the } \\
\text { preference to mathematics of students? }\end{array}$ & & & & & \\
\hline $\mathrm{C}_{5}$ & $\begin{array}{l}\text { What percentage does the lack of utility, from } \\
\text { mathematics, influence on the preference to } \\
\text { mathematics of students? }\end{array}$ & & & & & \\
\hline $\mathrm{C}_{6}$ & $\begin{array}{l}\text { What percentage does the mass media influence on } \\
\text { the preference to mathematics of students? }\end{array}$ & & & & & \\
\hline $\mathrm{C}_{7}$ & $\begin{array}{l}\text { What percentage does low socioeconomic status, } \\
\text { from mathematics students, influence on their } \\
\text { preference to learn mathematics? }\end{array}$ & & & & & \\
\hline $\mathrm{C}_{8}$ & $\begin{array}{l}\text { What percentage does the vocation, from students by } \\
\text { programs no linked to mathematics, influence on } \\
\text { their preference to learn mathematics? }\end{array}$ & & & & & \\
\hline
\end{tabular}

The interviewees responded according to following grey classes: $S_{1}=\left[0 ; 20>, S_{2}=\left[20 ; 40>, S_{3}=\left[40 ; 60>, S_{4}=[60 ; 80>\right.\right.\right.$, and $\mathrm{S}_{5}=[80 ; 100]$.

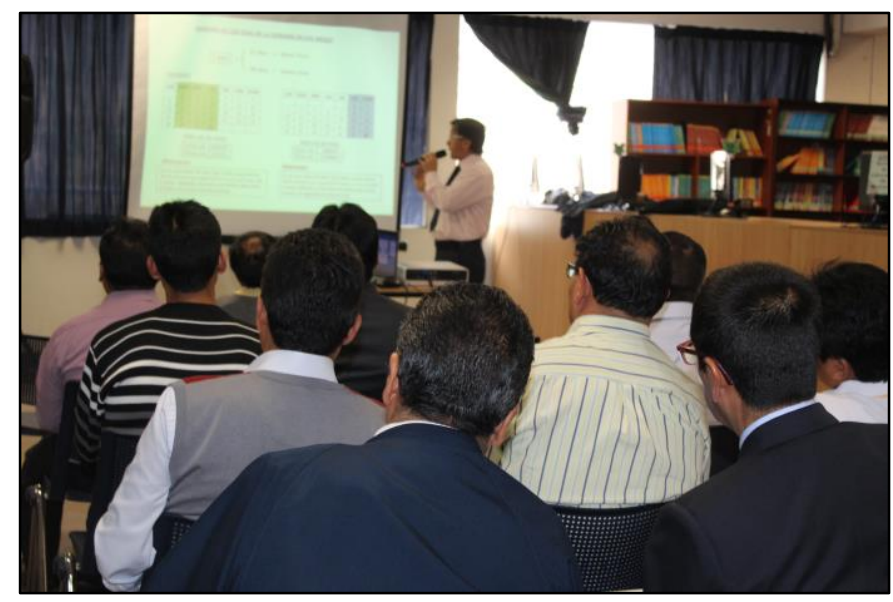

Fig. 2. Teacher in the final stage of CONAMAT in Peru.

Fig. 2 shows a part of teachers who also participated in a training on didactic of the mathematics after they responded the structured questionnaire used in this study. In addition, to develop trainings on didactic to teachers is very necessary in order to improve the acceptance of the mathematics by the secondary students.

The collected data from seventy-one teachers was aggregated using arithmetic media [12], the results are presented in Table II.

$1^{\text {th }}$ LACCEI International Multi-Conference for Engineering, Education, and Technology: "Industry, Innovation, And Infrastructure for Sustainable Cities and Communities”, 24-26 July 2019, Jamaica. 
TABLE II. COLLECTED DATA FROM TEACHERS

\begin{tabular}{|l|c|c|c|c|}
\hline Criterion & $\mathbf{C}_{\mathbf{1}}$ & $\mathbf{C}_{\mathbf{2}}$ & $\mathbf{C}_{\mathbf{3}}$ & $\mathbf{C}_{\mathbf{4}}$ \\
\hline Score & 53.63 & 61.25 & 63.09 & 64.06 \\
\hline Criterion & $\mathbf{C}_{\mathbf{5}}$ & $\mathbf{C}_{\mathbf{6}}$ & $\mathbf{C}_{\mathbf{7}}$ & $\mathbf{C}_{\mathbf{8}}$ \\
\hline Score & 56.12 & 59.58 & 37.75 & 50.54 \\
\hline
\end{tabular}

Now, the calculations for the case study, based on the steps of the CTWF method, are preceded as follows:

\section{Step 1:}

The center-points of the five grey classes were determined. The results are presented in Table III.

TABLE III. CENTER-POINTS OF GREY CLASSES

\begin{tabular}{|c|c|c|c|c|}
\hline $\mathbf{S}_{\mathbf{1}}$ & $\mathbf{S}_{\mathbf{2}}$ & $\mathbf{S}_{\mathbf{3}}$ & $\mathbf{S}_{\mathbf{4}}$ & $\mathbf{S}_{\mathbf{5}}$ \\
\hline$[0-20>$ & {$[20-40>$} & {$[40-60>$} & {$[60-80>$} & {$[80-100]$} \\
\hline$\lambda_{1}=10$ & $\lambda_{2}=30$ & $\lambda_{3}=50$ & $\lambda_{4}=70$ & $\lambda_{5}=90$ \\
\hline
\end{tabular}

Step 2:

The grey classes were extended in two directions adding grey classes $S_{0}$ and $S_{6}$ with their center-points $\lambda_{0}$ and $\lambda_{6}$ as shown in Table IV. Then, the triangular functions constructed according to center-points are presented in Fig. 4.

TABLE IV. EXTENDED GREY CLASSES IN THE CASE STUDY

\begin{tabular}{|l|l|c|c|c|c|c|}
\hline \multicolumn{7}{|c|}{ Center-points of the extended grey classes } \\
\hline $\boldsymbol{\lambda}_{\mathbf{0}}$ & $\boldsymbol{\lambda}_{\mathbf{1}}$ & $\boldsymbol{\lambda}_{\mathbf{2}}$ & $\boldsymbol{\lambda}_{\mathbf{3}}$ & $\boldsymbol{\lambda}_{\mathbf{4}}$ & $\boldsymbol{\lambda}_{\mathbf{5}}$ & $\boldsymbol{\lambda}_{\mathbf{6}}$ \\
\hline 0 & 10 & 30 & 50 & 70 & 90 & 100 \\
\hline
\end{tabular}

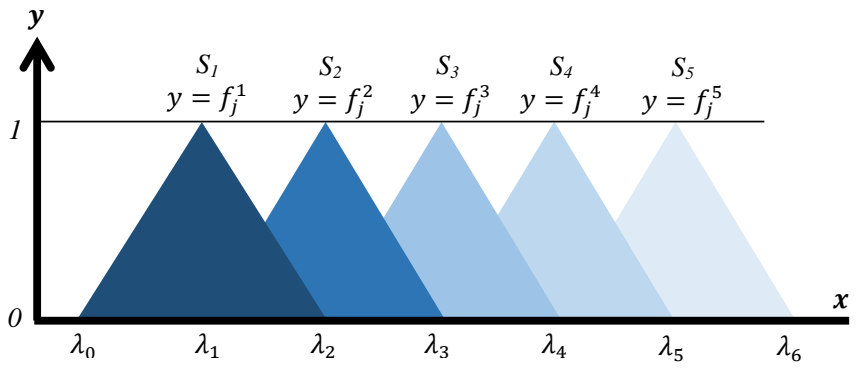

Fig. 3. Triangular functions for the case study

Then, the values presented in Table IV were substituted into Eq. 1, to obtain the CTWF of the five grey classes. The results are presented in Eqs. 3-7:

$$
\begin{gathered}
f_{\mathrm{j}}^{1}(x)= \begin{cases}\frac{0,}{\frac{x-0}{10},}, & x \notin[0,30] \\
\frac{30-x}{20}, & x \in[10,10]\end{cases} \\
f_{\mathrm{j}}^{2}(x)= \begin{cases}\frac{0,}{\frac{x-10}{20},}, & x \notin[10,50] \\
\frac{50-x}{20}, & x \in[10,30]\end{cases}
\end{gathered}
$$

$$
\begin{gathered}
f_{\mathrm{j}}^{3}(x)= \begin{cases}\frac{0,}{x-30} & x \notin[30,70] \\
\frac{70-x}{20}, & x \in[30,50]\end{cases} \\
f_{\mathrm{j}}^{4}(x)= \begin{cases}\frac{0,}{x-50} & x \notin[50,70] \\
\frac{90-x}{20}, & x \in[50,70]\end{cases} \\
f_{\mathrm{j}}^{5}(x)= \begin{cases}\frac{0,}{x-70}, & x \notin[70,100] \\
\frac{100-x}{10}, & x \in[70,90]\end{cases}
\end{gathered}
$$

Then, from Table II, the CTWF values of each criterion were calculated using Eqs. 3-7. The results of the functions values for each criterion are shown in Table V.

TABLE V. VALUES OF CTWF FOR EACH CRITERION

\begin{tabular}{|c|c|c|c|c|c|c|c|c|}
\hline $\mathbf{C}_{\mathbf{j}}$ & $\mathbf{C}_{\mathbf{1}}$ & $\mathbf{C}_{\mathbf{2}}$ & $\mathbf{C}_{\mathbf{3}}$ & $\mathbf{C}_{\mathbf{4}}$ & $\mathbf{C}_{\boldsymbol{5}}$ & $\mathbf{C}_{\mathbf{6}}$ & $\mathbf{C}_{\mathbf{7}}$ & $\mathbf{C}_{\boldsymbol{8}}$ \\
\hline $\boldsymbol{f}_{\boldsymbol{j}}^{\mathbf{1}}$ & 0.00 & 0.00 & 0.00 & 0.00 & 0.00 & 0.00 & 0.00 & 0.00 \\
\hline $\boldsymbol{f}_{\boldsymbol{j}}^{\mathbf{2}}$ & 0.00 & 0.00 & 0.00 & 0.00 & 0.00 & 0.00 & 0.61 & 0.00 \\
\hline $\boldsymbol{f}_{\boldsymbol{j}}^{\mathbf{3}}$ & 0.82 & 0.44 & 0.35 & 0.30 & 0.69 & 0.52 & 0.39 & 0.97 \\
\hline $\boldsymbol{f}_{\boldsymbol{j}}^{\mathbf{4}}$ & 0.18 & 0.56 & 0.65 & 0.70 & 0.31 & 0.48 & 0.00 & 0.03 \\
\hline $\boldsymbol{f}_{\boldsymbol{j}}^{\mathbf{5}}$ & 0.00 & 0.00 & 0.00 & 0.00 & 0.00 & 0.00 & 0.00 & 0.00 \\
\hline
\end{tabular}

\section{Step 3:}

In the final step, the results are calculated using a percentage system by application of Eq. 2. The results for each criterion are shown in Table VI.

TABLE VI. PORENTEGE SYSTEM FOR EACH CRITERION

\begin{tabular}{|c|c|c|c|c|c|c|c|c|}
\hline $\boldsymbol{\alpha}_{\mathbf{k}}$ & $\mathbf{C}_{\boldsymbol{1}}$ & $\mathbf{C}_{\mathbf{2}}$ & $\mathbf{C}_{\mathbf{3}}$ & $\mathbf{C}_{\mathbf{4}}$ & $\mathbf{C}_{\mathbf{5}}$ & $\mathbf{C}_{\mathbf{6}}$ & $\mathbf{C}_{\mathbf{7}}$ & $\mathbf{C}_{\mathbf{8}}$ \\
\hline $\mathbf{2 0}$ & 0.00 & 0.00 & 0.00 & 0.00 & 0.00 & 0.00 & 0.00 & 0.00 \\
\hline $\mathbf{4 0}$ & 0.00 & 0.00 & 0.00 & 0.00 & 0.00 & 0.00 & 24.50 & 0.00 \\
\hline $\mathbf{6 0}$ & 49.11 & 26.25 & 20.73 & 17.81 & 41.65 & 31.27 & 23.25 & 58.39 \\
\hline $\mathbf{8 0}$ & 14.52 & 45.00 & 52.36 & 56.25 & 24.46 & 38.30 & 0.00 & 2.14 \\
\hline $\mathbf{1 0 0}$ & 0.00 & 0.00 & 0.00 & 0.00 & 0.00 & 0.00 & 0.00 & 0.00 \\
\hline & $\mathbf{6 3 . 6 3}$ & $\mathbf{7 1 . 2 5}$ & $\mathbf{7 3 . 0 9}$ & $\mathbf{7 4 . 0 6}$ & $\mathbf{6 6 . 1 2}$ & $\mathbf{6 9 . 5 8}$ & $\mathbf{4 7 . 7 5}$ & $\mathbf{6 0 . 5 4}$ \\
\hline
\end{tabular}

\section{RESULTS AND DISCUSSION}

The results and discussion, according to specific objective in this study, are presented as follows:

\section{A. The case study}

From Table VI, the results for each criterion are shown in Fig. 4.

$17^{\text {th }}$ LACCEI International Multi-Conference for Engineering, Education, and Technology: "Industry, Innovation, And Infrastructure for Sustainable Cities and Communities”, 24-26 July 2019, Jamaica. 


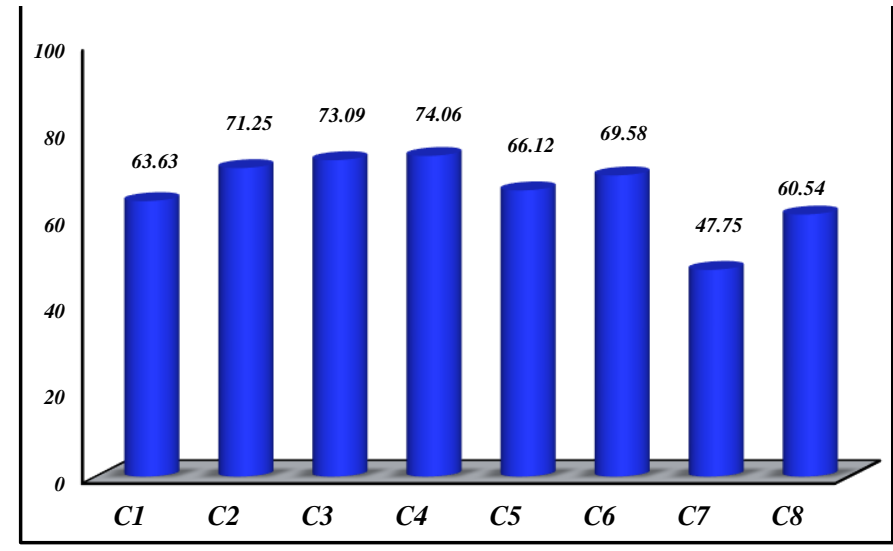

Fig. 4. Differences between stakeholder groups.

Fig. 4 shows the scores of the eight criteria; for example the maximum values were $74.06,73.09$, and 71.25 , which correspond to criteria $\mathrm{C} 4, \mathrm{C} 3$, and $\mathrm{C} 2$, respectively. Therefore, the mathematics teachers opined that the criteria C4 (knowledge from mathematics teacher), C3 (didactic from mathematics teacher), and $\mathrm{C} 2$ (motivation from mathematics teacher) were the most important criteria that influence on the preference to mathematics from secondary students. These results showed the teachers recognized that aspects as lack of knowledge, lack of didactic, and lack of motivation from teachers, impact on the preference of the students on mathematics.

Moreover, the criteria C7 (low socioeconomic status from students) and C8 (vocation from students by programs no linked to mathematics) were the criteria that less influenced on the preference on mathematics from students. This fact means that socioeconomic aspects and vocation for other programs different to mathematics did not influence on motivation to mathematics.

Therefore, it would be very recommendable that educational authorities from Peru government will implement programs and trainings to mathematics teachers, in order to improve their knowledge, didactic, and motivation to teach mathematics, as shown in Fig. 5. In addition, Fig. 5 shows a workshop on mathematical game in which the mathematical teachers participated. In this was, it is very important to indicate that in order to improve the motivation to mathematics, elements of mathematics game should be included during the teaching of the mathematics.

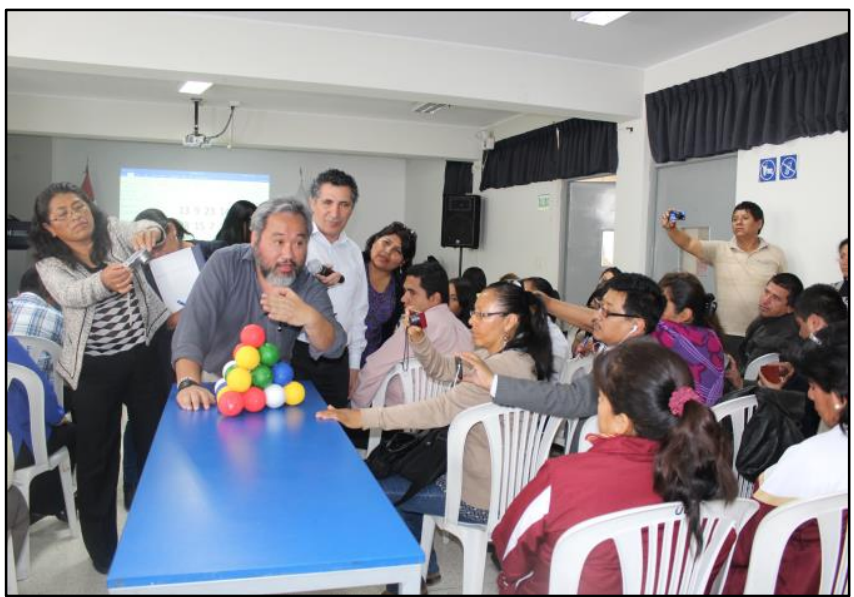

Fig. 5. Teachers participated in a mathematical game.

\section{B. The CTWF method}

Fist, the CTWF method showed its efficiency during its application on analysis of mathematics teaching from the point of the view of teachers. In addition, the CTWF, which is based on grey systems theory, considers the uncertainty within its analysis [5], this fact is an advantage regarding to others classical multi-criteria methods, such as the Delphi method or the analytic hierarchic process (AHP) [13].

Second, the CTWF method could be applied and tested on other research problems linked to social sciences or education sciences, as this method can be applied on problems with small samples or limited information [14].

\section{CONCLUSIONS}

The CTWF method showed interesting results during its application on analysis of teaching of mathematics from the point of the view of teachers. In addition, in future studies, the CTWF method could be applied on others studies from social sciences or educational sciences, as this method considers the uncertainty within its analysis.

The results of this study could help to teachers or educational authorities from Peru government to make the best decision, in order to improve teaching and learning of mathematics; as well as, this results could help to implement measures to improve the motivation of students to learning mathematics. Moreover, the mathematics is a topic very important to engineering learning; therefore, it is necessary that students get a good base of mathematics, in order to have success during their studies of engineering.

$1^{\text {th }}$ LACCEI International Multi-Conference for Engineering, Education, and Technology: "Industry, Innovation, And Infrastructure for Sustainable Cities and Communities”, 24-26 July 2019, Jamaica. 


\section{REFERENCES}

[1] C. W. Eilar, V. Jatla, M. S. Pattichis, C. LopezLeiva, and S. CeledonPattichis, "Distributed video analysis for the advancing out of school learning in mathematics and engineering project," in 2016 50th Asilomar Conference on Signals, Systems and Computers, 2016, pp. 571-575.

[2] T. Richter et al., "ViPLab - A Virtual Programming Laboratory for Mathematics and Engineering," in 2011 IEEE International Symposium on Multimedia, 2011, pp. 537-542.

[3] C. Stathopoulou, A. Chronaki, and P. Kotarinou, "Establishing the use of 'metre' as a measure unit: an interdisciplinary approach for teaching mathematics," Teach. Math. its Appl., vol. 33, no. 2, pp. 8197, Jun. 2014.

[4] Universidad de Ciencias y Humanidades, "CONAMAT," 2017. [Online]. Available: http://www.conamat.edu.pe/web/. [Accessed: 20-Apr-2017].

[5] S. Liu and Y. Lin, Grey Systems: Theory and Applications. Berlin: Springer, 2010.

[6] X. Tong and C. Baoming, "A experiments teaching model based on activity theory in office advanced application curriculum," in $20127 \mathrm{th}$ International Conference on Computer Science \& Education (ICCSE), 2012.

[7] Q. Xianyi, "Study on Higher Mathematics Teaching Model of Human-Computer Interaction in Campus Network," in 2009 Second International Symposium on Knowledge Acquisition and Modeling, 2009.
[8] A. Delgado and I. Romero, "Applying Grey Systems and Shannon Entropy to Social Impact Assessment and Environmental Conflict Analysis," Int. J. Appl. Eng. Res. ISSN, vol. 12, no. 24, pp. 973-4562, 2017.

[9] A. Delgado, "Citizen criminality assessment in lima city using the grey clustering method," in Proceedings of the 2017 IEEE 24th International Congress on Electronics, Electrical Engineering and Computing, INTERCON 2017, 2017.

[10] A. Delgado and E. C. Reyes, "Applying shannon entropy to select alternative plants as food for livestock: A case study in Ecuador," in 2016 IEEE Congreso Argentino de Ciencias de la Informática y Desarrollos de Investigación (CACIDI), 2016, pp. 1-5.

[11] P. Corbetta, Metodología y técnicas de investigación social. Madrid: McGRAW-HILL, 2007.

[12] J. Aznar and F. Guijarro, Nuevos métodos de valoración, modelos multicriterio, vol. 2 ${ }^{\mathrm{a}}$. Valencia: Universitat Politèctica de València, 2012.

[13] V. Campos-Climent, A. Apetrei, and R. Chaves-Ávila, "Delphi method applied to horticultural cooperatives," Manag. Decis., vol. 50, no. 7, pp. 1266-1284, 2012.

[14] Y. Zhang, J. Ni, J. Liu, and L. Jian, "Grey evaluation empirical study based on center-point triangular whitenization weight function of Jiangsu Province industrial technology innovation strategy alliance," Grey Syst. Theory Appl., vol. 4, no. 1, pp. 124-136, 2014.

$17^{\text {th }}$ LACCEI International Multi-Conference for Engineering, Education, and Technology: "Industry, Innovation, And Infrastructure for Sustainable Cities and Communities”, 24-26 July 2019, Jamaica. 